\title{
E-cigarettes: The Holy Grail of Smoking Cessation or a New Addiction?
}

\author{
Alexander Dufort ${ }^{1}$, Aida Owila ${ }^{1}$ \\ ${ }^{1}$ Faculty of Medicine, University of Ottawa
}

\author{
A B STRACT
}

Since its introduction, Electronic Cigarettes (E-cigarettes) have evoked strongly opposed views and much passion from both proponents and opponents. The proponents of e-cigarettes view the product as an effective smoking cessation tool and a potential savior for millions of smokers. They argue that the vapor based system in e-cigarettes is a much safer mode of nicotine delivery than the combustion system in conventional cigarettes. Opponents view E-cigarettes as a product that, at best, introduces new bad habits, renormalizes smoking and may even serve as a gateway to smoking in non-smokers.

The existing body of literature on the issue, while impressive, is far from conclusive. Much more needs to be determined about ecigarettes before informed decisions can be made about their safety and effectiveness. This article intends to summarize and analyze the scientific arguments raised from both perspectives on E-cigarettes.

\section{RÉ S U M É}

Depuis leur introduction, les cigarettes électroniques suscitent des opinions fortement opposées et beaucoup de passion, tant de la part des adeptes que des opposants. Les adeptes de la cigarette électronique considèrent le produit comme un outil efficace de sevrage du tabac et un moyen potentiel de sauver des milliers de fumeurs. Ils font valoir que le système à la vapeur des cigarettes électroniques est un dispositif beaucoup plus sécuritaire de libération de nicotine que le système à combustion traditionnel des cigarettes. Les opposants, quant à eux, perçoivent ce produit comme une source de nouvelles mauvaises habitudes, qui renormalise l'usage du tabac et peut même devenir une porte d'entrée au tabagisme chez les non-fumeurs.

Bien qu'imposante, la littérature sur le sujet est loin d'être concluante. Il y a beaucoup de réponses à trouver au sujet des cigarettes électroniques avant que l'on puisse prendre des décisions éclairées relativement à leur sécurité et leur efficacité. Le présent article vise à résumer et à analyser les arguments scientifiques soulevés par les deux perspectives de la cigarette électronique.

\section{INTRODUCTION}

Have you ever been at a bar and thought you saw someone smoking inside even though it's been banned for the past 10 years in Ontario? Ever wondered what those plastic cigarettes sold at corner stores were? Well if you've ever been in either of those situations, then you have probably been wondering about what is known as an Electronic Cigarette (E-cigarette). In simple terms, an E-cigarette allows a user to simulate smoking without "actually smoking". More technically, the E-cigarette contains a battery operated heating element, known as an atomizer (Figure 1), which allows the user to vaporize liquid containing flavouring and propylene glycol, with or without the addition of nicotine. Upon inhalation, the vaporization of the liquid delivers flavour/nicotine to the user while also producing vapour to simulate smoke. This technology is then wrapped in a sleek package commonly resembling an E-cigarette or a pen [1]. E-cigarettes are available with or without nicotine, but for the purposes of

Keywords: e-cigarettes, smoking cessation, addiction this article we will be focussing on nicotine containing devices as this is where most of the debate is centered. In Canada, nicotine containing E-cigarettes are not authorized for sale, however this is not strictly regulated or enforced; this leaves the device in a legal purgatory, allowing users to easily find and purchase nicotine containing products.

Worldwide, the E-cigarette industry is a booming operation, earning 3 billion dollars of sales revenue in 2013 [2]. E-cigarette use is also becoming increasing popular in Canada, with almost $1 / 5$ of Canadians having tried the product [3]. Despite the popularity, there is strong ongoing debate between advocates and critics, arguing whether or not these products are benign as advertised, or if they could have serious consequences. From one side of the argument, advocates of E-cigarettes claim the product can be a healthier alternative to traditional smoking and that they could be used effectively for smoking cessation. On the other hand, critics cite that not enough is known about the health effects of E-cigarettes. Of particular concern is the possible effects on youths who utilize these vaporizers. The current 


\section{Commentary}

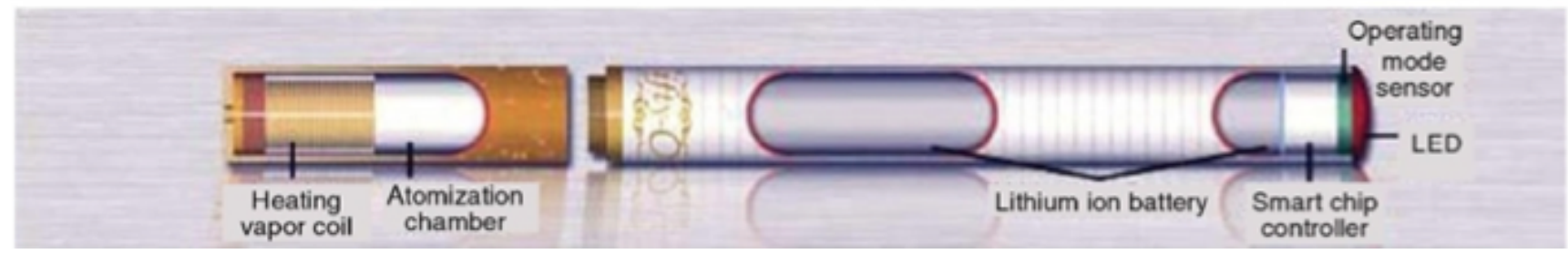

Figure 1: Schematic of an e-cigarette [35]

state of affairs has some health officials in Ontario calling for a ban on E-cigarette use in public places, similar to tobacco use, and a ban on E-cigarette sales to youths [4].

In this article, the debate on E-cigarettes will be summarized and analyzed from both perspectives, providing a holistic and balanced view of the discussion (see Figure 2).

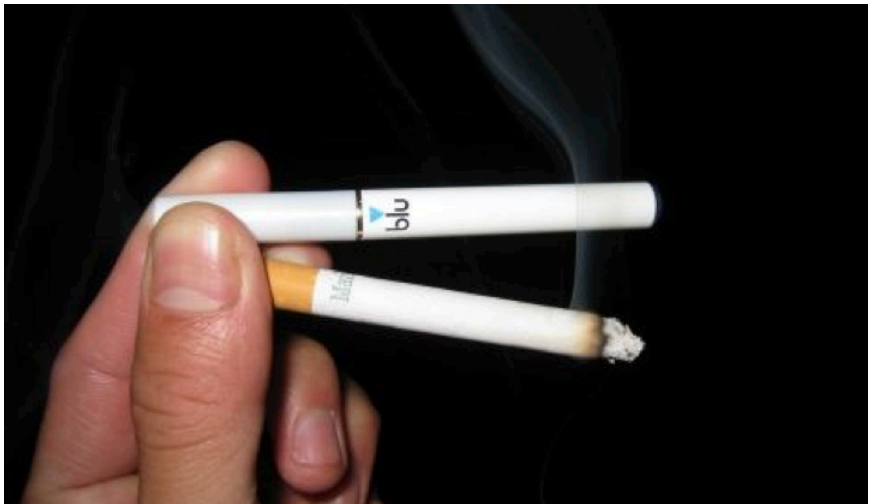

Figure 2: An image depicting cigarettes vs. e-cigarettes (http://greenecigarettes.wordpress.com)

\section{HEALTH EFFECTS}

The proponents of E-cigarettes claim that this innovative product has a considerable theoretical health advantage over conventional cigarettes. E-cigarettes function using a vapor based system and are battery operated, significantly reducing the toxic chemicals that are generated as a result of tobacco combustion. There are more than 4000 chemicals in tobacco smoke, many of which are known carcinogens and toxins [5]. Furthermore each puff contains millions of dangerous free radicals [6]. Opponents have raised issues with proximity of the E-cigarettes' metal body to the vapour and its potential contaminating effect. Analysis of E-cigarette vapour has revealed the presence of trace metals, such as nickel, lead and cadmium [7].

In a recent review of the existing data on the chemistry of aerosols and the liquids of E-cigarettes, the authors concluded that the contaminants were not significant enough to warrant any real health concerns [8]. Similarly, toxicological studies have shown significantly lower index of concern with regard to E-cigarettes' vapor compared to cigarette smoke [9]. The results suggest that the vapour based system utilized in E-cigarettes is in fact a better mode of nicotine delivery compared to the combustion system of conventional cigarettes.

Mode of delivery aside, the common substance between conventional and E-cigarettes that raises health concerns is nicotine. While nicotine is in fact an addictive substance, research suggests that nicotine's health effects may not be as alarming as it was once believed. The effects of nicotine on atherosclerotic heart disease, coronary circulation, platelet aggregation and lipid profile are minimal at best $[10,11,12,13]$. Research in other fields has suggested that nicotine use in adolescents can have a substantial negative impact on their developing brain [1]. Nicotine has also been implicated in many of the fetal development issues related to maternal smoking, including diabetes and obesity [14].

Even if E-cigarettes were proven to be safer than conventional cigarettes, is that really the right question to be asking? Perhaps it would be more appropriate to ask whether or not E-cigarettes are safe at all. It is important to understand the potential health effects of E-cigarettes, as at the moment they are poorly standardized, barely regulated and contain no warning label to alert potential users of their effects. Even though the focus of the arguments in the literature and the media has been on the relative safety of E-cigarettes to conventional cigarettes, there is a need for a shift of focus on the absolute safety of Ecigarettes.

In addition to nicotine, E-cigarette users can be exposed to various toxic chemicals, including diethylene glycol (anti-freeze), tobacco specific nitrosamines (carcinogens) and potentially harmful chemicals including, anabasine, myosmine, and $\beta$-nicotyrine [15]. It is true that these chemicals are present in much smaller quantities than in cigarette smoke and that their effects at lower doses are unknown. However, this should not detract from their potential harm until more data is available in the future. What we can be certain of for the time being is that many E-cigarette users report adverse events such as mouth irritation, cough, nausea and vomiting after only a short period of smoking [16]. Overall, the jury is still out on the health effects of E-cigarettes, particularly in the long run. Perhaps for now it would be wise to tighten regulation on these products and hold off on promoting them as healthier options until we have more concrete evidence.

\section{SMOKING CESSATION}

In the current Austerity era, psychiatrists represent One of the main marketing points of E-cigarettes is that they allow smokers to transition to a product that is very similar to cigarettes but without the harm of toxic chemicals. In effect, it is claimed that E-cigarettes can act as a smoking cessation tool. A few studies have been done and, for the most part, the results 
either show no effect or minimal benefit for individuals wanting to quit [1]. In fact, only one randomized control trial (RCT) has been done to examine this issue and it reported that E-cigarettes were no better than traditional nicotine replacement therapies [17]. Aside from the question of whether E-cigarettes can effectively help smokers quit, it is also important to examine if users are actually using the product to quit smoking. In a recent British study, only about $1 / 3$ of E-cigarette users intended on quitting smoking, the other $2 / 3$ either used E-cigarettes to cut down on cigarettes, or to have a product which allowed them smoke in public places [18]. While using an E-cigarette to cut down may seem beneficial, it is anticipated these health gains would be insignificant compared to the ones achieved from quitting altogether [2]. Currently, there does not seem to be enough evidence for E-cigarette manufacturers to make this claim, a view point which is also shared by the Canadian Medical Association (CMA), The World Health Organization (WHO) and British Medical Association (BMA).

While the RCT data is unimpressive, it is important to keep in mind that anecdotal evidence and surveys point to the success of E-cigarettes as cessation devices. One such survey demonstrated a cessation success rate of $31 \%$ with former smokers using E-cigarettes to quit [19]. Based on the results, the authors concluded that E-cigarettes hold promise as a tool for smoking-cessation and deemed it worthy of further research with more-rigorous design protocols. Furthermore, the existing body of literature suggests that certain patient populations may benefit from using E-cigarettes. This is particularly true in cases where traditional smoking cessation methods fail or are proven ineffective. First line oral medications for treatment of nicotine addiction are contraindicated in some conditions. For example, Varenicline and Bupropion carry a 'black-box' warning for some psychiatric conditions. Another population that potentially benefits from E-cigarettes are patients with Chronic Obstructive Pulmonary Disease (COPD). COPD is a progressive respiratory disease due to an inflammatory response to chronic tobacco smoke. Medical research to date suggests that COPD patients do not tend to respond well to traditional smoking cessation efforts and E-cigarettes may be beneficial [20]. Therefore E-cigarettes may be particularly worth considering for special populations.

\section{GATEWAY}

In countries where the treatment gap between mental As mentioned earlier, major proponents of E-cigarettes are advertising these products as the newest aid in smoking cessation. However, what is now being uncovered is that E-cigarettes may act as a gateway to cigarette use, specifically among adolescents. A recent study showed in a cross sectional analysis of almost 40,000 adolescents, that E-cigarette use did not discourage smoking and potentially encouraged cigarette use with a higher odds ratio of ever or current smoking [21]. Adolescents, who have tried E-cigarettes, were twice as likely to have intentions of smoking traditional cigarettes [22].

This concern is also compounded by the fact that the manufactures of E-cigarettes, many of which are traditional tobacco companies, can subvert traditional bans on tobacco advertising and market their products towards teenagers. This marketing is accomplished through television and online ads, as well as flavours and colours which are appealing to teenagers [23]. The amount of marketing has exploded in the last few years with the campaigns reaching an audience of 24 million adolescents in the United States alone [24]. This strategy has been proven to be effective as the number of American adolescents smoking E-cigarettes has doubled during 2011-2012 to 1.8 million [25]. There is also the concern that the widespread use of E-cigarettes will undermine efforts which have taken years to denormalize/ shun smoking, allowing the use of cigarettes to become socially acceptable again and possibly re-glamorize smoking for teenagers [26]. While more studies are needed to further assess these theories, it is very worrisome given the widespread use of Ecigarettes, and the lack of regulation surrounding the sales and marketing of these products.

The possibility of a gateway effect is clearly alarming, however, the research and statistics suggesting E-cigarettes as a gateway to smoking are far from conclusive and association not should be confused with causality. It is important to keep in mind that smoking statistics are highly dependent on geography and sociodemographic factors, and are thus limited in their representativeness of other countries, nationalities and socioeconomic backgrounds. In a recent study by Lee et al., 2014, the authors suggested that after adjusting for demographics, current cigarette smokers were much more likely to use E-cigarettes compared to non-smokers [27]. In fact, E-cigarette use was correlated with heavier and more recent smoking. Therefore, it is arguable that the response of adolescents to the marketing advertisements of E-cigarettes is not necessarily an undesirable outcome given that they are switching to a healthier mode of delivery. Additionally, the studies which have documented a possible gateway effect are retrospective in design and should be analysed with caution as they can only show association, not causation. While it has been reported that there is a significant increase in the number of adolescents who smoke e- cigarettes in the recent years, many of these studies do not account for teenagers who were already smokers of conventional cigarettes. Accounting for this baseline smoking status may mean that many of the reported alarming statistics are at least partially explained by the number of teenagers who are simply switching the mode of delivery. This would make it difficult to conclude that the E-cigarettes marketing advertisements are in fact causing non-smoking teenagers to smoke.

\section{ENVIRONMENTAL EFFECTS}

From an environmental perspective, conventional smoking is a major cause of residential fires. A recent survey estimated an annual average of 7600 smoking-related fires in residential buildings in the United States [28]. With smoking related fires accounting for $14 \%$ of fire deaths, and considering the thousands of residential fires every year, this issue has substantial safety and 
economic loss concerns associated with it. E-cigarettes are mostly operated with lithium batteries, which significantly reduce the risk of residential fires. There have been the occasional reports of battery explosions but they are often caused by improper use of the device or design defects and rarely result in serious injury. Similar to any other battery operated device, including cell phones, E-cigarettes have minimal risks associated with battery malfunctions and mishaps. These issues can be adequately addressed with better education of users on the proper use of this electronic device and increasing the standards of production and ensuring evidence based regulations.

Furthermore, discarding cigarette butts are currently a form of non-biodegradable litter. Cigarette butts thrown from sidewalks and moving cars end up in rivers and eventually oceans. The annual Ocean Conservancy's International Coastal Cleanup (ICC) reports that "cigarette butts have been the single most recovered item" with more than 1,684,183 cigarette butts collected in 2007 in US alone [29]. It is important to keep in mind that many of these products are toxic and degrade slowly, if at all, and thus will be diluted in the water and soil and potentially pose serious risk to the environment and the wild life. As more smokers transition to E-cigarettes, this environmental impact may be diminished [29].

While E-cigarettes have promising environmental implications, some questions remain to be answered. These concerns include the impact of E-cigarette battery disposal, the disposal of cartridges containing nicotine and the impact of factories dedicated to nicotine extraction and purification [30]. Before these concerns are addressed, it is premature to deem E-cigarettes as the safer environmental choice. On a smaller environmental scale, one of the common concerns of E-cigarettes is the effect of their vapor on indoor air quality. When an E-cigarette is used indoors, the vapor released has been found to contain not only nicotine, but also many other chemicals and additives, some of which may be possible carcinogens such as polycyclic hydrocarbons [31]. Though the levels of nicotine observed were ten times less than from conventional cigarettes, there are still possible health implications for adolescents and pregnant woman who are passively exposed [2,32]. Other then the gasses released, ultrafine particles (100-200 nm) have been documented in E-cigarette vapour. Exposure to these particles is worrisome as similar particulate matter has been associated with respiratory and cardiac illness [1]. Together, these effects on environmental air quality are prompting health officials to consider banning E-cigarette use in public establishments.

\section{CONCLUSION}

Research to date, for the most part, suggests that E-cigarettes are theoretically safer than conventional cigarettes and a possible alternative to the existing low efficacy methods available for smoking cessation $[33,34]$. However, by the virtue of the fact that E-cigarettes are relatively new products, long-term studies on their chronic health consequences are in effect non-existent.
More studies are needed to uncover the true health effects of E-cigarettes and their efficiency in achieving the ultimate goal of cessation in smokers. Furthermore, the safety of the hundreds of additives and flavors used in various E-cigarette products, their dose related risks and potential interactions with one another need to be better outlined by further research.

Concerns regarding E-cigarettes being a gateway to smoking in non-smokers, particularly young individuals, are alarming but not fully supported by the existing literature. The concerns stem from the marketing practices of tobacco companies who often advertise E-cigarettes as a glamorous and new cultural trend promoting the product as "what all the cool kids are doing these days" as opposed to a smoking cessation device (Figure 3). Even if E-cigarettes were to be promoted as a "safe" and "effective" therapeutic smoking cessation device, we are still a long way from knowing the true efficacy of E-cigarettes in longterm smoking cessation or the longitudinal effects of E-cigarettes on the health of its users.

There is no doubt that smoking cessation is the best option for every one of the countless smokers in the world. While noble, this may just be an unrealistic expectation to have of every patient you see in your clinic. It is important to empathize with the patient in their journey of smoking cessation. It is also essential and perhaps therapeutic to recognize that smoking cessation is a difficult task and that the current state of approved smoking cessation aids are far from ideal. By reducing some of the significant adverse health effects associated with the use of conventional cigarettes, E-cigarettes may just be the answer in saving the lives of millions of smokers worldwide and everyone they would be exposing to second hand smoke by extension. At least until we find better alternatives to aid smoking cessation. Further research in the area is needed before scientifically supported claims and informed decisions can be made regarding the safety of E-cigarettes use.

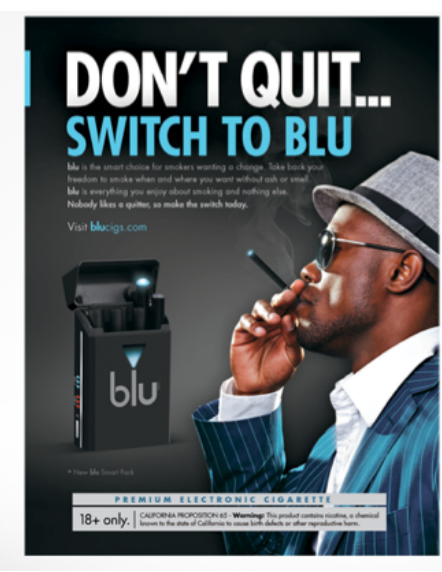

Figure 3: An example of an e-cigarette advertisement (http://ecigs-marketing.blogspot.ca/2014/01/why-quit-ad-brought-to-by-blu-ecig.html) 


\section{REFERENCES}

1. Grana R, Benowitz N, Glantz SA. E-cigarettes: a scientific review. Circulation 2014;129(19):1972-1986.

2. WHO. WHO framework convention on tobacco control. 2014.

3. Czoli CD, Hammond D, White CM. Electronic cigarettes in Canada: prevalence of use and perceptions among youth and young adults. Can J Public Health. 2014;105(2):97-102.

4. Millard FJ. The rising incidence of tuberculosis. J R Soc Med. 1996;89(9):497-500.

5. Environmental Protection Agency. Respiratory health effects of passive smoking: lung cancer and other disorders. 1992.

6. Pryor WA, Stone K. Oxidants in cigarette smoke. Radicals, hydrogen peroxide, peroxynitrate, and peroxynitrite. Ann N Y Acad Sci. 1993;686:12-27; 27-18.

7. Goniewicz ML, Kuma T, Gawron M, Knysak J, Kosmider L. Nicotine Levels in Electronic Cigarettes. Nicotine \& Tobacco Research. 2012;23(2):30-35

8. Burstyn I. Peering through the mist: systematic review of what the chemistry of contaminants in electronic cigarettes tells us about health risks. BMC Public Health. 2014;14(1):18.

9. Romagna G, Allifranchini E, Bocchietto E, Todeschi S, Esposito $M$, et al. Cytotoxicity evaluation of electronic cigarette vapor extract on cultured mammalian fibroblasts (ClearStream-LIFE): comparison with tobacco cigarette smoke extract. Inhal Toxicol. 2013;25(6):354-361.

10. Ambrose JA, Barua RS. The pathophysiology of cigarette smoking and cardiovascular disease: an update. J Am Coll Cardiol. 2004;43(10):1731-1737.

11. Nitenberg A, Antony I. Effects of nicotine gum on coronary vasomotor responses during sympathetic stimulation in patients with coronary artery stenosis. J Cardiovasc Pharmacol. 1999;34(5):694699.

12. Zevin S, Jacob P, 3rd, Benowitz NL. Dose-related cardiovascular and endocrine effects of transdermal nicotine. Clin Pharmacol Ther. 1998;64(1):87-95.

13. Ludviksdottir D, Blondal T, Franzon M, Gudmundsson TV, Sawe U. Effects of nicotine nasal spray on atherogenic and thrombogenic factors during smoking cessation. J Intern Med. 1999;246(1):6166.

14. Bruin JE, Gerstein HC, Holloway AC. Long-Term Consequences of Fetal and Neonatal Nicotine Exposure: A Critical Review. Toxicological Sciences. 2010;116(2):364-374.

15. FDA. Laboratory Analysis of Electronic Cigarettes 2014.

16. Chen I-L. FDA Summary of Adverse Events on Electronic Cigarettes. Nicotine \& Tobacco Research. 2012;15(2):615-6

17. Bullen C, Howe C, Laugesen M, McRobbie H, Parag V, et al. Electronic cigarettes for smoking cessation: a randomised controlled trial. The Lancet. 2013;382(9905):1629-1637.

18. Dockrell M, Morison R, Bauld L, McNeill A. E-Cigarettes: Prevalence and Attitudes in Great Britain. Nicotine \& Tobacco Research.
$2013 ; 15(10): 1737-44$

19. Siegel MB, Tanwar KL, Wood KS. Electronic cigarettes as a smoking-cessation: tool results from an online survey. Am J Prev Med. 2011;40(4):472-475.

20. Schiller JS, Ni H. Cigarette smoking and smoking cessation among persons with chronic obstructive pulmonary disease. Am J Health Promot. 2006;20(5):319-323.

21. Dutra LM, Glantz SA. Electronic cigarettes and conventional cigarette use among U.S. adolescents: a cross-sectional study. JAMA Pediatr. 2014;168(7):610-617.

22. Bunnell RE, Agaku IT, Arrazola R, Apelberg BJ, Caraballo RS, et al. Intentions to smoke cigarettes among never-smoking U.S. middle and high school electronic cigarette users, National Youth Tobacco Survey, 2011-2013. Nicotine Tob Res. 2014.

23. McCarthy M. E-cigarette companies target youth, US congressional study finds. BMJ. 2014

24. Duke JC, Lee YO, Kim AE, Watson KA, Arnold KY, et al. Exposure to electronic cigarette television advertisements among youth and young adults. Pediatrics. 2014;134(1):e29-36.

25. CDC. E-cigarette use more than doubles among U.S. middle and high school students from 2011-2012. 2013.

26. CMA. 8th National Report Card on Health Care. 2008

27. Lee S, Grana RA, Glantz SA. Electronic Cigarette Use Among Korean Adolescents: A Cross-Sectional Study of Market Penetration, Dual Use, and Relationship to Quit Attempts and Former Smoking. Journal of Adolescent Health.54(6):684-690.

28. Administration UF (2012) Smoking-related Fires in residential buildings (2008-2010).

29. Novotny T, Lum K, Smith E, Wang V, Barnes R. Cigarettes Butts and the Case for an Environmental Policy on Hazardous Cigarette Waste. International Journal of Environmental Research and Public Health. 2009;6(5):1691-1705.

30. Chang $\mathrm{H}$. Research gaps related to the environmental impacts of electronic cigarettes. Tob Control. 2014;23 Suppl 2:ii54-58.

31. Schober W, Szendrei K, Matzen W, Osiander-Fuchs H, Heitmann D, et al. Use of electronic cigarettes (e-cigarettes) impairs indoor air quality and increases FeNO levels of e-cigarette consumers. Int $J$ Hyg Environ Health. 2014;217(6):628-637.

32. Czogala J, Goniewicz ML, Fidelus B, Zielinska-Danch W, Travers MJ, et al. Secondhand Exposure to Vapors From Electronic Cigarettes. Nicotine \& Tobacco Research. 2013.

33. udkin P, Hey K, Roberts S, Welch S, Murphy M, et al. Abstinence from smoking eight years after participation in randomised controlled trial of nicotine patch. BMJ. 2003;327(7405):28-29.

34. Moore D, Aveyard P, Connock M, Wang D, Fry-Smith A, et al. Effectiveness and safety of nicotine replacement therapy assisted reduction to stop smoking: systematic review and meta-analysis.2009;22(33):568-580

35. Wollscheid KA, Kremzner ME. Electronic cigarettes: safety concerns and regulatory issues. Am J Health Syst Pharm. 2009;66(19):17401742. 